\title{
Tuberculosis: una dinámica continua entre el pasado y el presente, para imaginar el futuro
}

\author{
FELIPE CABELLO C. ${ }^{1,2}$
}

\section{Tuberculosis: steady dynamics between past and present to imagine the future}

Progress in understanding the biological processes that allow Mycobacterium tuberculosis to be a successful parasite have accelerated in the last twenty years. This progress has been stimulated by the return of tuberculosis (TB) as an important disease in industrialized countries, by its increase in emergent nations in the tail of population increases and poverty and by the spread of multiple drug resistant (MDR) and extensively drug resistant (XDR) M. tuberculosis as a result of treatment failures. Progress on M. tuberculosis biology has also been fueled by advances in microbiology and molecular biology, including molecular genetics, genomics, proteomics and in vitro and in vivo models of infection. The study of latency or dormancy, a phenomenon central to understanding the persistence of $M$. tuberculosis and the development of $T B$ in individuals, its spread in human populations and the emergence of antibioticresistant/tolerant organisms, has been preferred targets for investigators in this area. In this manner, factors that trigger M. tuberculosis latency (e. g., hypoxia, nutrient starvation, NO exposure) have been characterized and the metabolic shifts to host lipid utilization, tolerance to antimicrobials and resistance to host immune mechanisms involved in latency have been determined. Similarly, genetic changes and the resulting antimicrobial mechanisms mediating the MDR and XDR states have been characterized and potential new vaccines that avoid reactivation from latency and infection are being developed. Despite this progress, and given the fact that effective anti tuberculosis therapy was developed and first introduced clinically at the end of the 1940s, there are now more cases of latent and active TB worldwide than ever before. This reinforces the concept of TB as a bacterial disease with strong social and economical determinants which are presently stimulating increased transmission in many human groups, undermining diagnostics, treatment and prevention. It suggests that in a scenario of global economical crisis the struggle against TB will be weakened, unless efforts are included to alleviate poverty, decrease economic inequality, improve public health and allow democracy and political organization.

(Rev Med Chile 2011; 139: 829-832).

Key words: Drug resistance, microbial; Genetic variation; Latent tuberculosis.

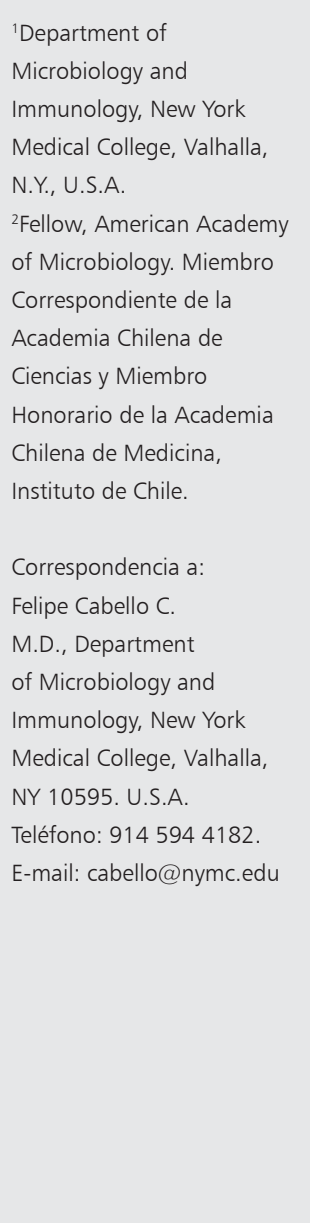

L a lectura de la tercera edición del excelente texto "Tuberculosis" ha servido para recordar diversas facetas de este flagelo, cuya historia ilumina desde épocas incluso anteriores a R.T.H. Laennec, aspectos noveles del desarrollo científico, de la medicina y de la salud pública. Como expuse en el año 2000 en la Conferencia
Anual de la Fundación Dr. Hernán Alessandri Rodríguez titulada "Los postulados de Koch y la genética molecular", el descubrimiento por Robert Koch de la etiología bacteriana de numerosas enfermedades infecciosas, incluyendo la tuberculosis (TBC), causó un giro único en la historia de la causalidad de la enfermedad. Este giro, acompaña- 
do por la formulación de los famosos "postulados de Koch", influye hasta hoy en el estudio de la etiología de las enfermedades infecciosas, donde estos postulados se aplican exitosamente para identificar los genes y las moléculas envueltas en el proceso patológico ocasionado por diversos microorganismos ${ }^{2}$.

La productiva unión entre la genética molecular y el estudio de las enfermedades infecciosas genera conocimientos novedosos de gran utilidad práctica en el tratamiento y la prevención de estas patologías, incluyendo la TBC. Por ejemplo, recientemente se publicó una investigación que desgraciadamente debilita el principio que indicaba que la monoterapia con isoniazida $u$ otros antibacterianos para la quimioprofilaxis de la TBC podía hacerse con cierta seguridad de que no se seleccionarían bacterias resistentes a ellas ${ }^{3}$. Esto, porque en la infección latente el número de bacterias es reducido y ellas se encuentran "adormecidas" y sin multiplicarse rápidamente, condiciones que desfavorecerían la aparición de mutantes de todo tipo, incluyendo las de resistencia a los antibacterianos ${ }^{3}$. Sin embargo, en este trabajo-que empleó la poderosa capacidad de determinar repetida y rápidamente la secuencia total de ADN del cromosoma del Mycobacteriun tuberculosis (Mtb)- los autores concluyen que en lesiones de tuberculosis latentes en macacos la bacteria conserva la capacidad para mutar, por un mecanismo al parecer diferente del de la TBC activa, y que esta capacidad es similar a la que se encontraría en bacterias creciendo velozmente en las paredes aireadas de una caverna en el pulmón ${ }^{3}$. El análisis de la secuencia del tipo de mutación indicó, además, que las mutaciones son probablemente el resultado de la interacción del daño oxidativo del ADN bacteriano producido por los radicales libres de oxígeno generados por las células inmunes del huésped y por la necesidad del Mtb de reparar este daño, para sobrevivir esta actividad antibacteriana ${ }^{3}$. Las conclusiones de este trabajo fueron posibles como resultado del consorcio de tecnología "de punta”, como la secuenciación rápida y repetida del ADN bacteriano con el experimento clásico de la fluctuación de la mutación bacteriana de Luria y Delbruck ${ }^{4}$. Este último experimento generó también el fundamento teórico del efectivo tratamiento asociado para prevenir la resistencia en TBC, planteado en las décadas de 1940 y 1950 por J. Crofton, G. Middlebrook, W. McDermott, G. Canetti y otros ${ }^{4,5}$.
La latencia del Mtb también influye poderosa y negativamente en su epidemiología, dada la capacidad de las lesiones latentes de reactivarse, producir enfermedad y amplificar el contagio. Por esto, y porque aproximadamente un tercio de la población mundial ( 1,8 billones) transporta lesiones latentes de la infección, existe un enorme interés en caracterizar este proceso de latencia y de encontrar maneras efectivas de prevenirlo y bloquearlo. De esta forma, en los últimos años la investigación se ha centrado en estudiar los estímulos y los mecanismos usados por la bacteria para entrar en latencia ${ }^{6,7}$. Así, se han identificado factores como la carencia de nutrientes y la hipoxia que, activando complejas redes genéticas, producen giros regulatorios que alteran el metabolismo bacteriano y favorecen la latencia ${ }^{6,7}$. Por ejemplo, la hipoxia estimula la síntesis de una molécula reguladora DosR, que a su vez estimula la síntesis de un regulón necesario para subsistir la hipoxia y también para neutralizar los radicales libres de nitrógeno producidos por los macrófagos, uniéndose de esta manera fisiológicamente la latencia con la resistencia a mecanismos antibacterianos del huésped ${ }^{6,7}$. Estudios similares también han sugerido que durante la latencia la bacteria comienza a metabolizar los lípidos del huésped e introduce la acetil CoA de esta manera generada al ciclo de Krebs, a través de la estimulación del cortocircuito del glioxalato ${ }^{6}$.

La latencia también se caracteriza por la tolerancia del Mtb a los antibacterianos y al parecer esto sucede también por mecanismos fenotípicos alternativos a las mutaciones que generalmente subyacen en la resistencia bacteriana clásica a estos compuestos ${ }^{8}$. Recientemente, la tomografía computarizada y la tomografía por emisión de positrones han permitido caracterizar una gran diversidad en las lesiones de TBC latentes y plantear la hipótesis que la TBC latente estaría constituida por un amplio rango de alteraciones patológicas, que incluirían tanto lesiones de TBC activa como lesiones correspondientes a las clásicas de una TBC latente ${ }^{7}$, sugiriendo todos estos hallazgos la necesidad de hacer cambios en el diagnóstico y en la terapia de la latencia, considerado hasta ahora un tipo único de $\mathrm{TBC}^{7}$. Es así que la investigación básica en TBC se ha centrado en la búsqueda de antibacterianos y vacunas alternativas que sean capaces no sólo de prevenir la infección sino que también de prevenir la reactivación de los Mtb en 
las lesiones consideradas latentes ${ }^{7}$. Publicaciones recientes sugieren que ha sido posible diseñar una vacuna que, además de proteger contra la infección primaria, protegería en contra de la reactivación de la bacteria en las lesiones latentes en modelos animales ${ }^{9}$. Esto establecería las bases potenciales para diseñar y desarrollar una vacuna de uso humano bastante superior al $\mathrm{BCG}^{9,10}$. Es pertinente señalar que este progreso en comprender la biología de la TBC y del Mtb ha sido posible en gran medida por la aplicación de los postulados moleculares de Koch al estudio del Mtb y al consorcio de estos postulados con la genética microbiana, la genómica, la inmunología, los modelos animales y la clínica de la enfermedad.

Está claro de la lectura de la literatura que el progreso en comprender la biología del Mtb en los últimos 20 años ha sido exponencial y que este progreso fue estimulado por el retorno de la TBC como problema de salud pública en países industrializados. Sin embargo, a pesar de estos avances, aproximadamente dos millones de personas mueren anualmente de tuberculosis en el mundo y cada cuatro segundos una persona se infecta con $\mathrm{Mtb}$, produciéndose 9 millones de nuevos casos cada año. Además, nunca habían existido tantos casos de TBC en el mundo, debido especialmente al crecimiento de la población mundial ${ }^{11,12}$. Es evidente también que desde fines de la década de 1940 se contó con la tecnología adecuada para tratar efectivamente a la TBC y para potencialmente disminuirla y erradicarla, sin que infelizmente esto haya sucedido. Sin lugar a dudas esto se explica porque la causa de la TBC como enfermedad es irreducible al resultado simple de los postulados de Koch, ya que el Mtb es solamente la causa necesaria pero insuficiente para la producción de ella ${ }^{11,12}$, como ha sido manifiestamente demostrado una vez más por la reciente recrudescencia de la TBC en los países industrializados y en los de la antigua Unión Soviética y de la Europa oriental ${ }^{11,12}$. En la génesis de la TBC participan factores sociales, políticos y económicos que son tan cardinales como el Mtb para generarla y perpetuarla, convirtiéndola en una enfermedad social, resultado de la pobreza y de la exclusión y de inadecuadas políticas sociales y económicas, además de la falta de voluntad política para eliminarla ${ }^{11,12}$. Observaciones recientes también parecen sugerir que el paradigma médico tecnológico "tratar para prevenir", basado en el estrecho concepto de que la TBC es solamente una enfermedad infecciosa bacteriana, está siendo coartado en su habilidad en resolver el problema por los perjudiciales determinantes sociales y económicos de la enfermedad ${ }^{11,12}$.

De acuerdo con T. McKeown, la TBC comenzó a disminuir en el mundo industrializado junto con otras enfermedades infecciosas, antes de que existiera un tratamiento adecuado, asignándosele un rol importante en este descenso a la elevación de los niveles de vida, incluyendo la nutrición, la vivienda y la educación ${ }^{13}$. Recientemente se ha indicado que las negativas condiciones económicas y sociales, además de facilitar directamente la trasmisión de la TBC y socavar su diagnóstico y tratamiento, favorecen la presencia de factores que influyen sobre su evolución, incluyendo SIDA, tabaquismo, alcoholismo, la diabetes y la polución aérea en el hogar y el ambiente externo ${ }^{11,12}$. En un contexto de crisis económica y social global, que incluso se ha extendido a países como Irlanda, España, Grecia y Portugal, de desigualdad económica extrema y en aumento, como en nuestro país, con la presencia de aproximadamente más de 300.000 nuevos casos anuales de TBC en Europa Oriental y América Latina, con frecuentes Mtb con resistencia antimicrobiana múltiple y extensa y con aumentos de la polución atmosférica en ciudades como Santiago, es indudable que es prematuro pensar que la TBC vaya a disminuir como problema de salud pública en el futuro cercano, usando en la aproximación a ella solamente el modelo iniciado por R. Koch. Pareciera que lo que se necesitará para revertir esta grave situación será agregar a este modelo los planteamientos de una voz también del pasado, la de Rene Dubos, quien planteó claramente en su libro "La plaga blanca" que para lidiar con la TBC "es necesario comprender el impacto que en su génesis tienen los factores económicos y sociales tanto como los mecanismos usados por el Mtb para causar daño".

Agradecimientos. Agradezco sus comentarios a este texto, al Profesor Victorino Farga C. y a la Dra. Katia Velázquez M. Sin embargo, el contenido del texto es de mi exclusiva responsabilidad.

\section{Referencias}

1. Cabello F. Reseña Bibliográfica. Tuberculosis. $3^{\text {ra }}$ Edición. Victorino Farga y Jose A. Caminero. Rev Med Chile 2011; 139: 682-3. 
2. Falkow S. Molecular Koch's postulates applied to microbial pathogenicity. Rev Infect Dis 1988; Suppl 2: S274-6.

3. Ford CB, Lin PL, Chase MR, Shah RR, Iartchouk O, Galagan J, et al. Use of whole genome sequencing to estimate the mutation rate of Mycobacterium tuberculosis during latent infection. Nat Genet 2011; 43: 482-6.

4. Luria SE. Recent advances in bacterial genetics. Bacteriol Rev 1947; 11: 1-40.

5. Crofton J, Mitchison DA. Streptomycin resistance in pulmonary tuberculosis. BMJ 1948; 1009-15.

6. Russell DG. Mycobacterium tuberculosis and the intimate discourse of a chronic infection. Immunol Rev 2011; 240: 252-68.

7. Barry $3^{\text {rd }} \mathrm{CE}$, Boshoff HI, Dartois V, Dick T, Ehrt S, Flynn $\mathrm{J}$, et al. The spectrum of latent tuberculosis: rethinking the biology and intervention strategies. Nat Rev Microbiol 2009; 7: 845-55.

8. Baek S-H, Li AH, Sassetti CM. Metabolic regulation of mycobacterial growth and antibiotic sensitivity. PLoS Biol 2011; e1001065.
9. Aagaard C, Hoang T, Dietrich J, Cardona P-J, Izzo A, Dolganov $\mathrm{G}$, et al. A multistate tuberculosis vaccine that confers efficient protection before and after exposure. Nat Med 2011; 17: 189-94.

10. Kaufmann SH, Hussey G, Lambert P-H. New vaccines for tuberculosis. Lancet 2010; 375: 2110-9.

11. Lonnroth, K, Jaramillo E, Williams BG, Dye C, Raviglione M. Drivers of tuberculosis epidemics: The role of risk factors and social determinants. Social Sci Med 2009; 68: 2240-6.

12. Lönnroth K, Castro KG, Chakaya JM, Chauhan LS, Floyd $\mathrm{K}$, Glaziou P, et al. Tuberculosis control and elimination 2010-50: cure, care, and social development. Lancet 2010; 375: 1814-29.

13. Cabello F. Los roles del ambiente, de la higiene, de la epidemiología y de las vacunas en el desafío de las enfermedades infecciosas. [The roles that the environment, the sanitary conditions, the epidemiology and vaccines play in the challenge of infectious diseases]. Rev Chil Infect 2010; 27: 565-9. 